\title{
Experimental Harmonic Analysis of a Network of Adjustable Speed Drives
}

\author{
Makbul Anwari, M. I. M. Rashid, M. Imran Hamid \\ Faculty of Electrical Engineering \\ Universiti Teknologi Malaysia \\ Skudai, Johor, Malaysia
}

\author{
Taufik \\ Electrical Engineering Department \\ Cal Poly State University \\ San Luis Obispo, CA 93407, USA
}

\begin{abstract}
Harmonic analysis of a network of Adjustable Speed Drives (ASDs) has been experimentally investigated. A smallscale laboratory of the network of two ASDs connected to two induction motors was setup. Load of motor 1 was fixed while load of motor 2 was varied. In the experiment, measurements have been done at both side of power transformer to analyze power system harmonic.
\end{abstract}

Keywords- Adjustable Speed Drives; harmonics

\section{INTRODUCTION}

Inverter is a conversion process with power electronics that is generally known as the switched-mode inversion. One major application of switched-mode is Adjustable Speed Drive (ASD). ASD is an electronic device that controls the rotational speed of motor-driven equipment such as fans, pumps, and compressors. By ensuring that the motor's speed is accurately matched to the load placed on the motor, an ASD helps to save energy. Speed control is achieved by adjusting the frequency of the voltage applied to the motor. That is why they also called ASDs as Variable Frequency Drives (VFDs). ASD is becoming a significant load component for power distribution systems [1]. However, there are some cons to ASD systems, mainly the harmonics created by the power electronic components in the ASD. Harmonics are created by the switching system of the power electronic circuit inside the drive and can cause damage to power equipment on the utility side and sensitive loads on the customer side.

The effects of harmonics on voltage stability of power systems and how adjustable speed drives affect these harmonics have been studied. It is shown that the total power consumed by the motor with adjustable speed drives is greater than the motor alone and therefore the system is more prone to voltage instability. This paper also comprise that addresses several issues related to the effect of ASDs on distribution systems: 1) the influence of harmonics on the increased power, and 2) the influence of harmonics on the motor load in voltage stability studies [2].

Because of this, the Institute of Electrical and Electronic Engineers (IEEE) has developed standards for the amount of harmonic distortion a customer's load can inject back into the utility lines. To conform to this relatively new established guideline, it is a common practice nowadays for VFD systems to have line filters installed before them to reduce distortion caused by the VFDs back to the line. Doing so will therefore maintain a degree of power quality at the distribution level. More importantly, these line filters will also prevent the harmonic distortion to propagate back and further up at the transmission level. In this paper, a laboratory setup consist of two ASDs system connected to two induction motors was established to perform the measurement.

\section{LABORATORY SETUP}

The experimental setup of this research consists of two power supplies. The first source of energy supply to the drive was from the grid - transformer system. The second source of energy supply to the drive was from the photovoltaic inverter system. Those two power supplies were connected to two adjustable speed drives of $0.5 \mathrm{hp}$ and $1.5 \mathrm{hp}$. Each of adjustable speed drives (ASD) powered two separate induction motors. $0.5 \mathrm{hp} \mathrm{ASD}$ powered $0.25 \mathrm{hp}$ induction motor that was referred as motor 1 whereas $1.5 \mathrm{hp}$ ASD powered $2 \mathrm{hp}$ induction motor that was referred as motor 2. Load of motor 1 was fixed at $25 \%$ torque and load of motor 2 was varied for $0 \%$ to $\leq 50 \%$ torque.

In this research, there were two types of experiment that have been carried out. Figure 1 shows the block diagram of laboratory setup. They are simplified diagram of the system indicating the labeling convention of the data and graphs. All experiments were conducted under room temperature. Figure 1 shows energy supply from grid and photovoltaic systems have been used.

The experiment that was carried out in the laboratory is shown in Figure 1 in which used both energy supplies from grid and photovoltaic system were connected to the loads. Measurements were recorded at both side of power transformer at point $\mathrm{C}$, and $\mathrm{D}$ to analyze power quality in these systems. In conducting the experiment, frequency of the system and load motor 2 (Carpanelli) were varied from $40 \mathrm{~Hz}$ to $70 \mathrm{~Hz}$ and 0 to $\leq 50 \%$ of load whereas load motor 1 (Feedback) was fixed at $25 \%$ of load. Each time data collection was completed, the data was compiled into graphs to monitor the difference of harmonics distortion based on location and percentage of the rated load. 


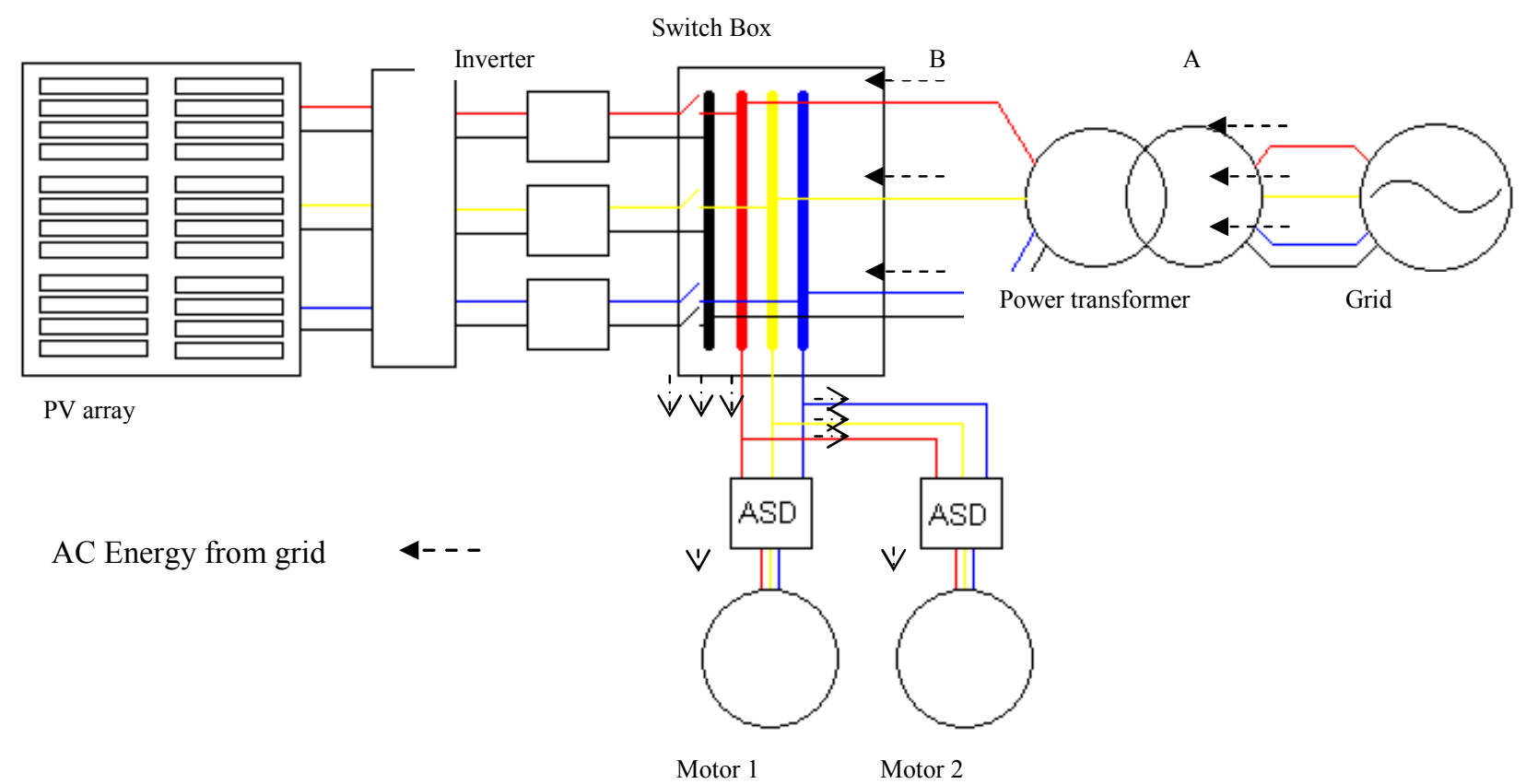

Fig. 1. Experimental setup diagram block

Table 1 lists the equipments that have been installed in the laboratory:

TABLE I

EQUIPMENTS USED FOR LABORATORY SETUP

\begin{tabular}{|c|c|c|}
\hline Unit & Equipment & Rating \\
\hline 1 & Power transformer & $3 \mathrm{kVA}$ \\
\hline 2 & ASD(Omron Varispeed V7) & $1.1 \mathrm{~kW} \& 0.3 \mathrm{~kW}$ \\
\hline 1 & Induction motor1 (Feedback) & $1 / 4 \mathrm{Hp}$ \\
\hline 1 & Break System & $24 \mathrm{~V}, 1.24 \mathrm{~A}, 25 \mathrm{Nm}$ \\
\hline 1 & Torque Adjustable(TAL-100V) & $100 \mathrm{~V}$ \\
\hline 1 & Induction motor2 (Carpanelli) & $2 \mathrm{Hp}$ \\
\hline 1 & Resistive load bank(NE 7026) & $3 \mathrm{Kw}$ \\
\hline 1 & Load measurement(De Lorenzo) & $0.75 \mathrm{~kW}, 3.4 \mathrm{~A}$ \\
\hline
\end{tabular}

\section{EXPERIMENTAL RESULTS}

Figures 2 to 13 show trends in THDv and THDi with regards to M2 torque load percentages at both side power transformer which in point A for primary and B for secondary.

\section{Analysis of Voltage Distortion}

In this experiment, THDv for grid connection is shown in graphs as in figure $2,4,6,8,10$, and 12 . In general, for measurements at point $\mathrm{A}$, in comparison, increases at a steady rate as it appears to be less affected by disturbances or inconsistencies in all measurements. This makes sense since the transformer after point $\mathrm{A}$ functions as harmonic filter that blocks harmonic energy to creep back to the ac system [1]. For measurement at point $\mathrm{B}$, graphs of THDv at point $\mathrm{B}$ almost same pattern at point $\mathrm{A}$ for all different frequency. When the frequency increases, THDv also increases for all points.

\section{Analysis of Current Distortion}

The analysis of current distortion is important, especially since the power quality issues relating to harmonic distortion of the current waveform are the responsibility of the customer compared to voltage distortion in which much of the responsibility of maintaining a clean voltage waveform lies on the utility [3]. For analysis of the current distortion, the THDi for grid connection is shown in graphs as in figure 3, 5, 7, 9, 11, and 13. The graphs at point A and B shows that THDi is generally lower at higher loads for all different frequency. This evident in the graphs because both an increase along the M2 torque load axis and the data sets related with higher torque loads produce THDi measurements that are smaller in value for all different frequency. 


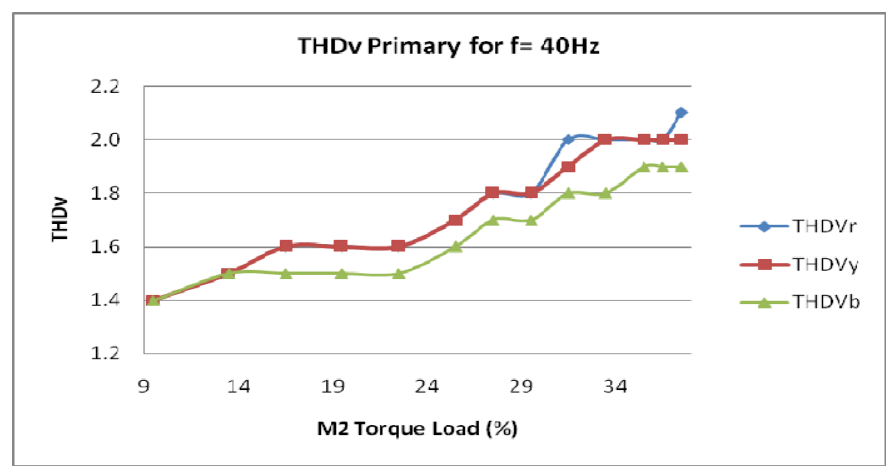

Fig. 2. THDv vs M2 torque load at point A for M1 at $25 \%$ of rated torque.

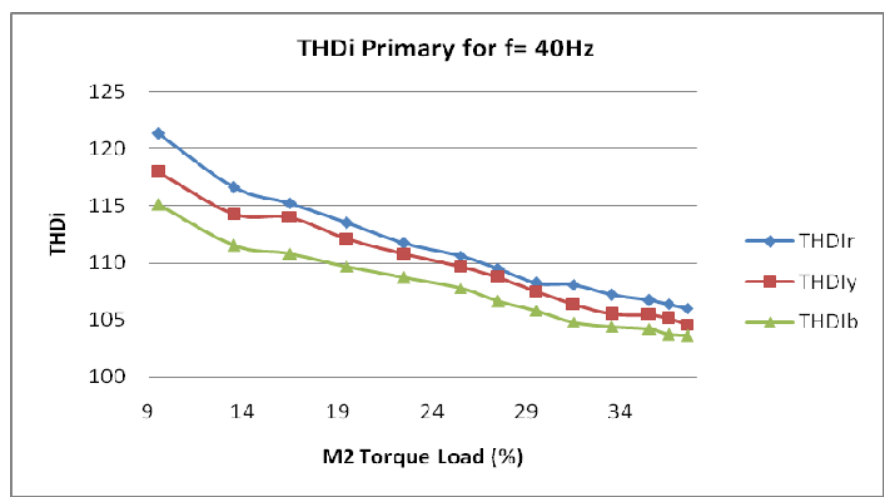

Fig. 3. THDi vs M2 torque load at point A for M1 at $25 \%$ of rated torque.

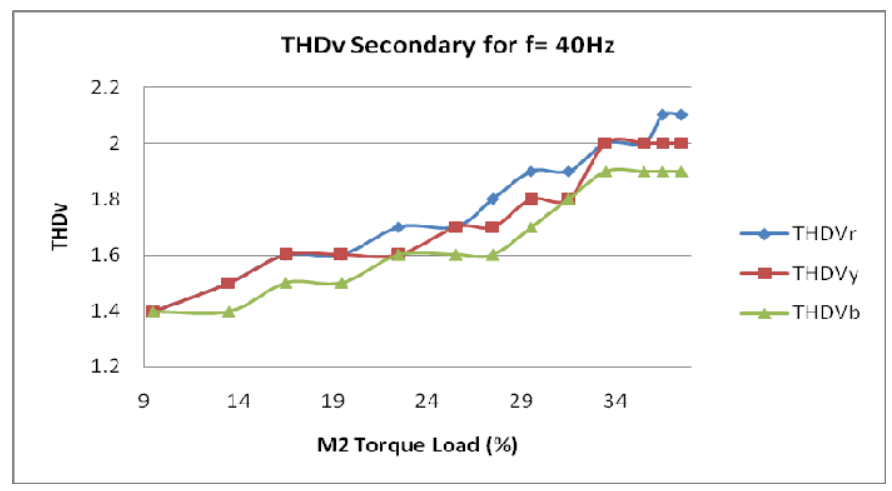

Fig. 4. THDv vs M2 torque load at point B for M1 at $25 \%$ of rated torque.

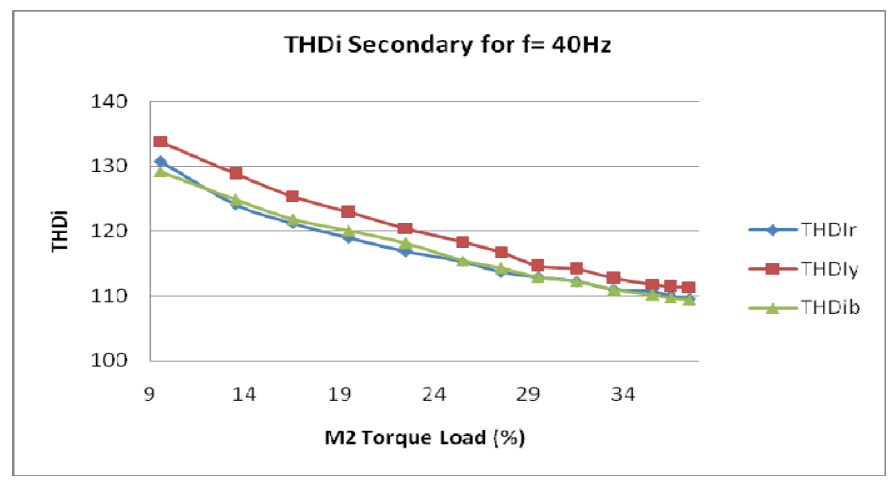

Fig. 5. THDi vs M2 torque load at point B for M1 at $25 \%$ of rated torque

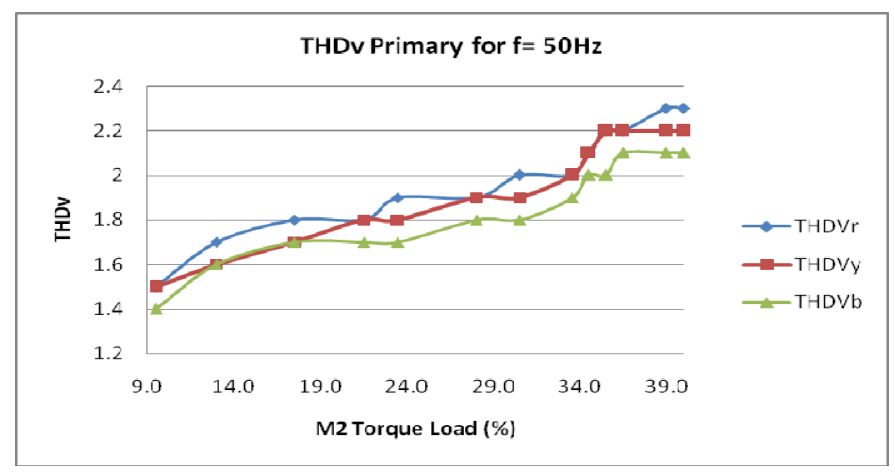

Fig. 6. THDv vs M2 torque load at point A for M1 at 25\% of rated torque.

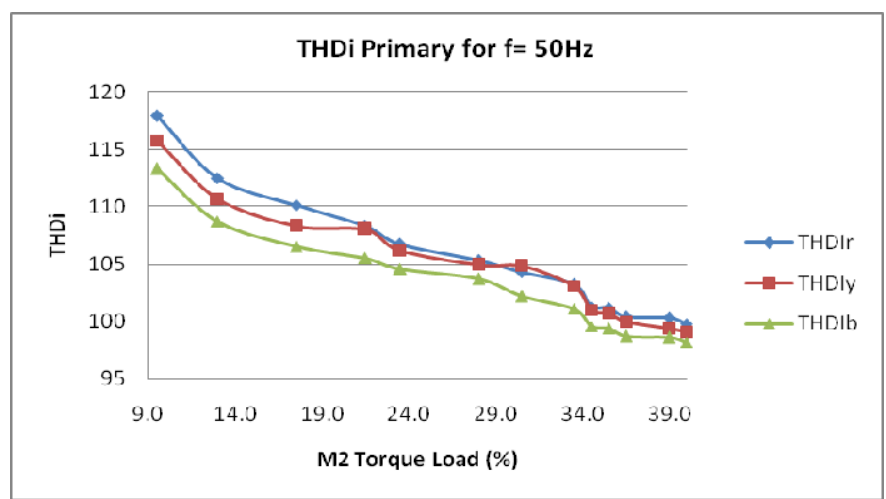

Fig. 7. THDi vs M2 torque load at point A for M1 at $25 \%$ of rated torque.

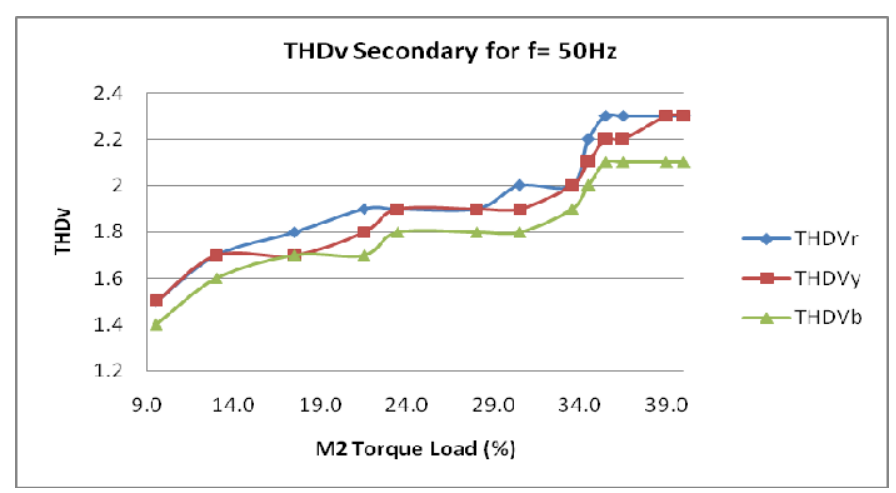

Fig. 8. THDv vs M2 torque load at point B for M1 at 25\% of rated torque.

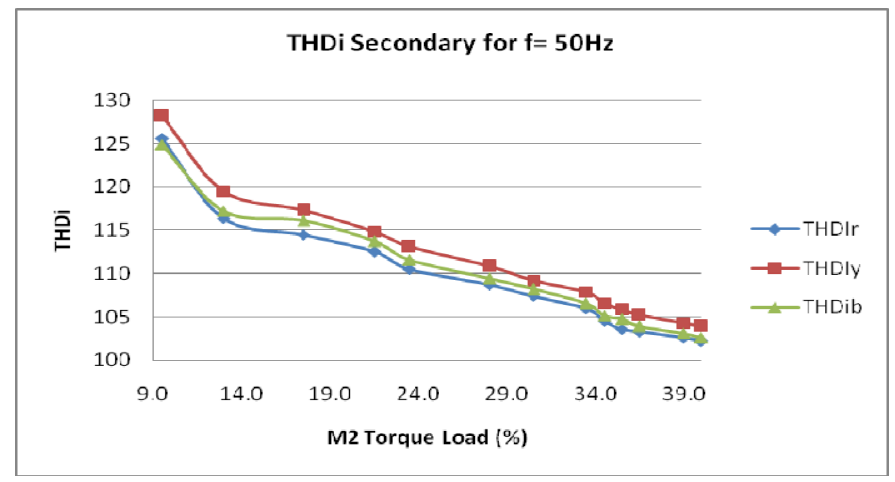

Fig. 9. THDi vs M2 torque load at point B for M1 at $25 \%$ of rated torque. 


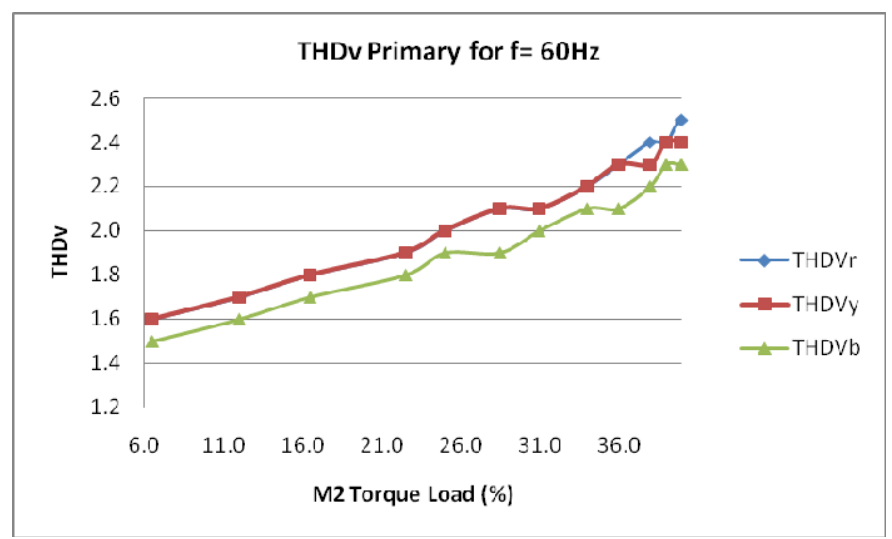

Fig. 10 . THDv vs $\mathrm{M} 2$ torque load at point $\mathrm{A}$ for $\mathrm{M} 1$ at $25 \%$ of rated torque.

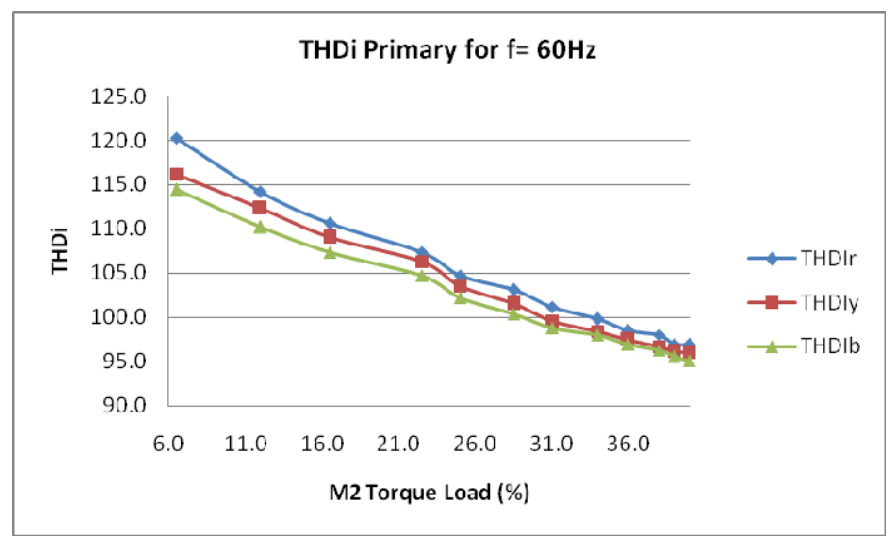

Fig. 11. THDi vs M2 torque load at point A for M1 at $25 \%$ of rated torque.

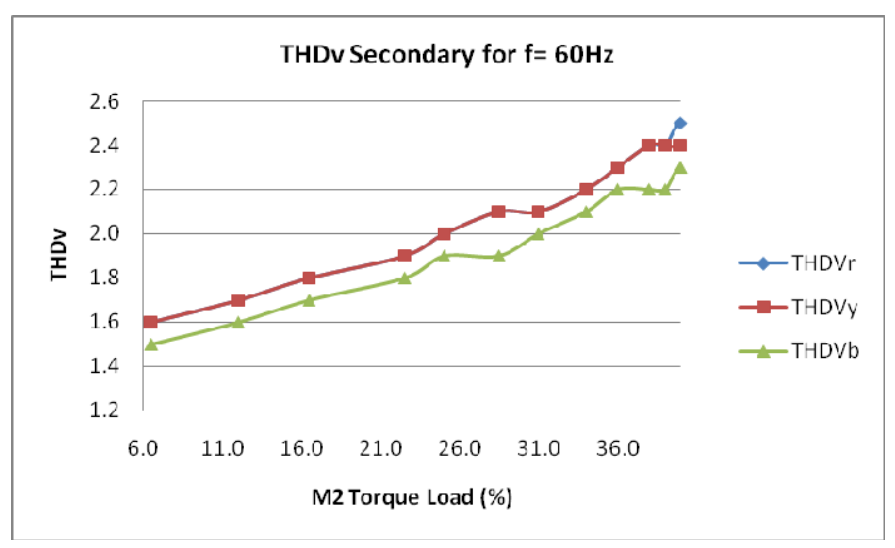

Fig. 12. THDv vs M2 torque load at point B for M1 at $25 \%$ of rated torque.

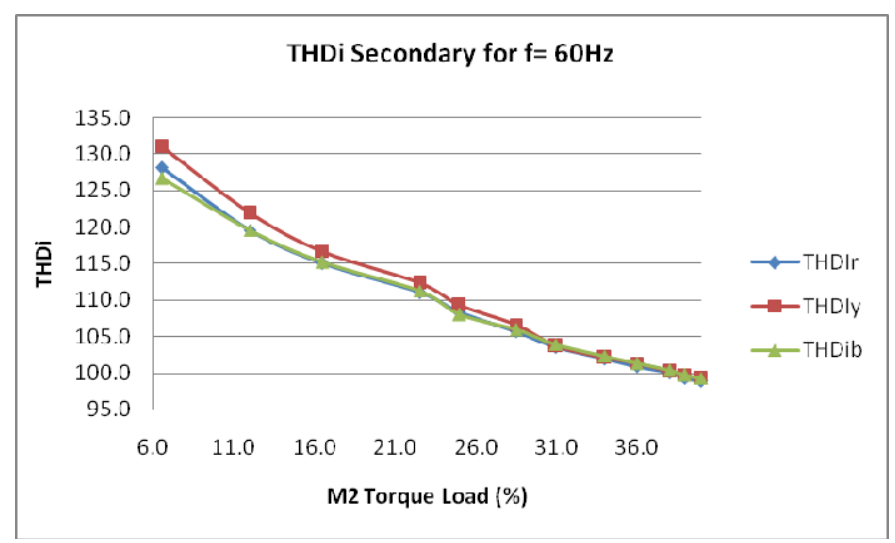

Fig. 13. THDi vs M2 torque load at point B for M1 at $25 \%$ of rated torque.

\section{CONCLUSIONS}

The analysis of the data shows trends in the harmonics behavior in the network of adjustable speed drives connected to induction motors and can be used to analyze power quality impact to the grid system. Additionally, this research can be used to reduce the higher total harmonic distortion in power system with a network of adjustable speed drives based on worst case operating scenarios.

\section{REFERENCES}

[1]. C. Mitsui, S. Tu, Taufik, and M. Anwari, "Efficiency Study of Adjustable Speed Drive with Dual Motor Connection," Proc. IEEE International Power Engineering Conference (IPEC), December 2007.

[2]. F. Jurado, N. Acero, A. López, J. I. Rojas, "Adjustable Speed Drives and Voltage Stability", Proc. IEEE International Electric Machines and Drives Conference, 2001.

[3]. IEEE Std 519-1992, IEEE Recommended Practices and Requirements for Harmonic Control in Electrical Power Systems, New York, NY: IEEE. 